\title{
Redshift Caused by Acceleration Doppler Effect and Hubble's Law Based on Wu's Spacetime Accelerating Shrinkage Theory
}

\author{
Edward T. H. Wu \\ Solar Buster Corporation, Los Angeles, USA
}

Email address:

edwardthwu@yahoo.com

To cite this article:

Edward T. H. Wu. Redshift Caused by Acceleration Doppler Effect and Hubble's Law Based on Wu's Spacetime Accelerating Shrinkage Theory. American Journal of Modern Physics. Vol. 6, No. 1, 2017, pp. 10-15. doi: 10.11648/j.ajmp.20170601.12

Received: January 9, 2017; Accepted: January 18, 2017; Published: March 4, 2017

\begin{abstract}
Acceleration Doppler Effect is introduced to explain the Redshift phenomenon in Inertia Transformation process. Hubble's Law and Cosmological Redshift are interpreted by Wu's Spacetime Accelerating Shrinkage Theory. In addition, Wu's Laws of Spacetime of Wu's Pair and Photon with respect to the age of universe and the gravitational field are derived and summarized.
\end{abstract}

Keywords: Yangton, Yington, Wu's Pair, Photon, Acceleration Doppler Effect, Cosmological Redshift, Hubble's Law, Universe Expansion, Spacetime Shrinkage

\section{Introduction}

Like most Scientists, I first thought that Redshift [1] and Doppler Effect [2] can only exist in the Non-Inertia Transformation process [3] as that in sound propagation. Because of this reason, I claimed that "Photon emitted from the light source travels in vacuum space at an Absolute Light Speed $3 \times 10^{8} \mathrm{~m} / \mathrm{s}$ observed at the light origin in Absolute Space System without any influence from the light source" in my previous publication [3]. But, this conflicts to my logical thinking. It is hard to believe that "A ball throw out of a train will not follow the train". The concept that photon emission is a Non-Inertia Transformation kept on bothering me for a long time until the "Acceleration Doppler Effect" is developed with Inertia Transformation to solve the problem. In addition, I have developed Wu's Spacetime, Spacetime Shrinkage and Spacetime Accelerating Shrinkage Theories [4] to explain Gravitational Redshift and Cosmological Redshift phenomena [5]. As a consequence, Wu's Accelerating Spacetime Shrinkage Theory can be used successfully to explain Hubble's Law [6]. All of the above issues will be discussed in details in this paper.

\section{Photon Emission}

According to Yangton and Yington Theory [7], photon is generated through a two stage Separation and Ejection process to release Wu's Pair from its parent substance (Figure 1) [8].

A. Separation Stage - Wu's pair is unlocked from its lockin position at the end of a string structure (parent substance).

B. Ejection Stage - The unlocked Wu's Pair is ejected by the repulsive force between the two Yangton and two Yington particles at the end of the string structure (Figure 1).

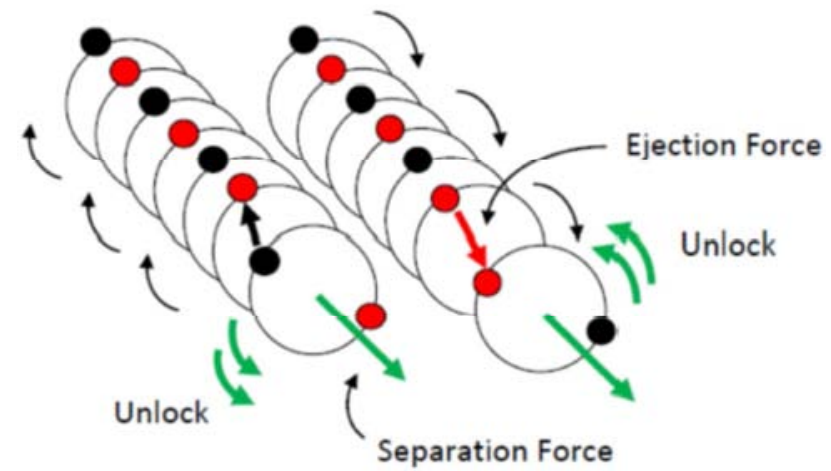

Figure 1. Photon Formed in a two stage process by releasing Wu's Pair from its Parent Substance. 


\subsection{Absolute Light Speed}

Because of the same ejection force, regardless to the frequency, the speed of a photon escaped from its parent source should always have a constant speed $3 \times 10^{8} \mathrm{~m} / \mathrm{s}$ (Absolute Light Speed) in the ejection direction observed at light source.

\subsection{Inertia Transformation}

Photon emitted from the separation and ejection process carries the inertia of the light source. In other words, a photon, emitted from a light source to a vacuum space, travels not only at the Absolute Light Speed $3 \times 10^{8} \mathrm{~m} / \mathrm{s}$ in its ejection direction, but also it is dragged to the same direction at the same speed as that of the light source when observed at light origin in Absolute Space System. This phenomenon is named as "Inertia Transformation".

\section{Vision of Light}

The vision of a photon observed by an observer can be constructed by superimposing observer's position in each time frame onto observer's final position in Absolute Space System. This vision of photon is named as "Vision of Light" [3]. Figure 2 shows the schematic diagrams of the Visions of Light of an emitted photon with respect to the observers at light origin, ground and light source in Absolute Space System, where ground and light source are drifted apart from light origin due to the motions of Earth $\left(\mathrm{V}_{\mathrm{E}}\right)$ and light source $\left(\mathrm{V}_{\mathrm{C}}\right)$. After a time interval $\Delta \mathrm{t}$, assuming all motions are at constant speeds, the Visions of Light of those observers can be represented by the following straight lines: AP-the Vision of Light observed by the observer at light origin (black line), BP-the Vision of Light observed by the observer at ground (red line) and CP-the Vision of Light observed by the observer at light source (green line) respectively. They are all ended at the final position of the emitted photon (point $\mathrm{P}$ ).

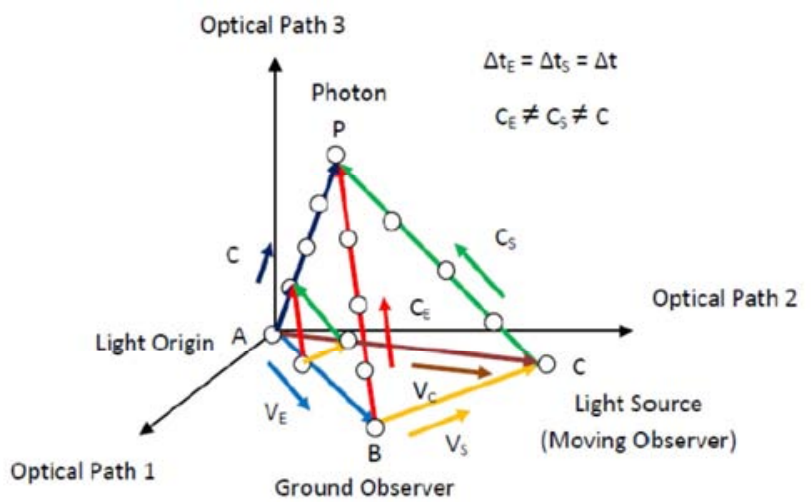

Figure 2. Visions of Light of an emitted photon observed by observers at light origin (black line), ground (red line) and light source (green line) in Absolute Space System.

As a result of Inertia Transformation, $\mathrm{CP}$-the Vision of Light observed by the observer at light source has a constant light speed $3 \times 10^{8} \mathrm{~m} / \mathrm{s}\left(\mathrm{C}_{\mathrm{S}}\right)$ in its ejection direction. AP-the Vision of Light observed by the observer at light origin is the actual trace of the emitted photon in Absolute Space System which is the vector summation of AC-the motion of light source and $\mathrm{CP}$-the Vision of Light observed by the observer at light source. Also, $\mathrm{C}_{\mathrm{O}}$-light speed observed at light origin is the vector summation of $\mathrm{C}_{\mathrm{S}}-$ the light speed observed at light source $\left(3 \times 10^{8} \mathrm{~m} / \mathrm{s}\right)$ and $\mathrm{V}_{\mathrm{C}}$ - the moving speed of light source.

$$
\begin{aligned}
& \mathrm{AP}=\mathrm{AC}+\mathrm{CP} \\
& \mathbf{C}_{\mathrm{O}}=\mathbf{C}_{\mathrm{S}}+\mathbf{V}_{\mathrm{C}}
\end{aligned}
$$

Because the speed of light is calculated by the Vision of Light divided by the traveling time of light, and the traveling time is the same for all observers, therefore the light speed observed by each observer is proportional to the length of the corresponding Vision of Light.

\section{Acceleration Doppler Effect}

Since the observer always stays in stationary to the light origins of all photons emitted from the light source, the Vision of Light of each photon observed by observer is the same as that observed at the light origin of the photon in the Absolute Space System.

Light source (star) can either move toward or away from the observer. $V_{o}$ is the speed of the light source at beginning, $\mathrm{V}_{\mathrm{t}}$ is the speed of the light source at time $\mathrm{t}$ when photon reaches Earth and a is the constant acceleration of the light source. $\mathrm{S}_{t}$ is the distance of the light source traveling from the light origin in time $t, P_{t}$ is the distance of the photon traveling in the ejection direction from the light origin in time $t, V_{0} t$ is the distance of the photon dragged by the light source in time $t$ and $D_{t}$ is the distance between the photon and the light source at time t. And $\lambda_{1}$ is the wavelength, $v_{1}$ is the frequency and $C_{1}$ is the light speed observed by the observer on Earth. Zeroshift, Blueshift and Redshift phenomena resulted from Acceleration Doppler Effect can thus be derived by mathematics as follows:

\subsection{Zeroshift}

When the light source (star) either moves toward or away from the observer at a constant speed $\left(\mathrm{V}_{\mathrm{o}}=\mathrm{V}_{\mathrm{t}}\right.$ and $\left.\mathrm{a}=0\right)$, Zeroshift can be detected.

In case the light source (star) moves away from the observer,

$$
\begin{gathered}
\mathrm{S}_{\mathrm{t}}=\mathrm{V}_{\mathrm{o}} \mathrm{t} \\
\mathrm{P}_{\mathrm{t}}=\mathrm{Ct}-\mathrm{V}_{\mathrm{o}} \mathrm{t} \\
\mathrm{D}_{\mathrm{t}}=\mathrm{S}_{\mathrm{t}}+\mathrm{P}_{\mathrm{t}}=\mathrm{Ct}
\end{gathered}
$$

Therefore,

$$
\begin{gathered}
\lambda_{1}=\mathrm{D}_{\mathrm{t}} / \mathrm{ft}=\mathrm{Ct} / \mathrm{ft}=\mathrm{C} / \mathrm{f}=\lambda \\
\mathrm{C}_{1}=\mathrm{P}_{\mathrm{t}} / \mathrm{t}=\left(\mathrm{Ct}-\mathrm{V}_{\mathrm{o}} \mathrm{t}\right) / \mathrm{t}=\mathrm{C}-\mathrm{V}_{\mathrm{o}}<\mathrm{C}
\end{gathered}
$$




$$
v_{1}=\mathrm{C}_{1} / \lambda_{1}=\left(\mathrm{C}-\mathrm{V}_{\mathrm{o}}\right) / \lambda<v
$$

When the light source (star) moves away from the observer at a constant speed, the wavelength maintains unchanged, but both frequency and light speed become smaller. However, since $\mathrm{V}_{\mathrm{o}} \ll \mathrm{C}, \mathrm{C}_{1} \approx \mathrm{C}$ and $v_{1} \approx v$. Zeroshift can be detected.

In case the light source (star) moves toward the observer,

$$
\begin{gathered}
\mathrm{S}_{\mathrm{t}}=-\mathrm{V}_{\mathrm{o}} \mathrm{t} \\
\mathrm{P}_{\mathrm{t}}=\mathrm{Ct}+\mathrm{V}_{\mathrm{o}} \mathrm{t} \\
\mathrm{D}_{\mathrm{t}}=\mathrm{S}_{\mathrm{t}}+\mathrm{P}_{\mathrm{t}}=\mathrm{Ct}
\end{gathered}
$$

Therefore,

$$
\begin{gathered}
\lambda_{1}=\mathrm{D}_{\mathrm{t}} / \mathrm{ft}=\mathrm{Ct} / \mathrm{ft}=\mathrm{C} / \mathrm{f}=\lambda \\
\mathrm{C}_{1}=\mathrm{P}_{\mathrm{t}} / \mathrm{t}=\left(\mathrm{Ct}+\mathrm{V}_{\mathrm{o}} \mathrm{t}\right) / \mathrm{t}=\mathrm{C}+\mathrm{V}_{\mathrm{o}}>\mathrm{C} \\
v_{1}=\mathrm{C}_{1} / \lambda_{1}=\left(\mathrm{C}+\mathrm{V}_{\mathrm{o}}\right) / \lambda>v
\end{gathered}
$$

When the light source (star) moves toward the observer at a constant speed, the wavelength maintains unchanged, but both frequency and light speed become bigger. However, since $\mathrm{V}_{\mathrm{o}} \ll \mathrm{C}, \mathrm{C}_{1} \approx \mathrm{C}$ and $v_{1} \approx v$. Zeroshift can be detected.

\subsection{Blueshift}

In case the light source (star) moving toward the observer at a constant acceleration speed,

$$
\begin{gathered}
S_{t}=-\left(V_{o} t+1 / 2 a t\right) \\
P_{t}=C t+V_{o} t \\
D_{t}=S_{t}+P_{t}=C t-1 / 2 \text { at }
\end{gathered}
$$

Therefore,

$$
\begin{gathered}
\lambda_{1}=\mathrm{D}_{\mathrm{t}} / \mathrm{ft}=(\mathrm{Ct}-1 / 2 \mathrm{at}) / \mathrm{ft}=(\mathrm{C}-1 / 2 \mathrm{a}) / \mathrm{f}<\lambda \\
\mathrm{C}_{1}=\mathrm{P}_{\mathrm{t}} / \mathrm{t}=\left(\mathrm{Ct}+\mathrm{V}_{\mathrm{o}} \mathrm{t}\right) / \mathrm{t}=\mathrm{C}+\mathrm{V}_{\mathrm{o}}>\mathrm{C} \\
v_{1}=\mathrm{C}_{1} / \lambda_{1}=\left(\mathrm{C}+\mathrm{V}_{\mathrm{o}}\right) /((\mathrm{C}-1 / 2 \mathrm{a}) / \mathrm{f})>v
\end{gathered}
$$

When the light source (star) moves toward the observer at a constant acceleration speed, the wavelength becomes smaller, both the frequency and light speed become bigger, and thus Blueshift can be detected.

\subsection{Redshift}

In case the light source (star) moving away from the observer at a constant acceleration speed,

$$
\begin{gathered}
\mathrm{S}_{\mathrm{t}}=\mathrm{V}_{\mathrm{o}} \mathrm{t}+1 / 2 \text { at } \\
\mathrm{P}_{\mathrm{t}}=\mathrm{Ct}-\mathrm{V}_{\mathrm{o}} \mathrm{t} \\
\mathrm{D}_{\mathrm{t}}=\mathrm{S}_{\mathrm{t}}+\mathrm{P}_{\mathrm{t}}=\mathrm{Ct}+1 / 2 \text { at }
\end{gathered}
$$

Therefore,

$$
\lambda_{1}=\mathrm{D}_{\mathrm{t}} / \mathrm{ft}=(\mathrm{Ct}+1 / 2 \mathrm{at}) / \mathrm{ft}=(\mathrm{C}+1 / 2 \mathrm{a}) / \mathrm{f}>\lambda
$$

$$
\begin{gathered}
\mathrm{C}_{1}=\mathrm{P}_{\mathrm{t}} / \mathrm{t}=\left(\mathrm{Ct}-\mathrm{V}_{\mathrm{o}} \mathrm{t}\right) / \mathrm{t}=\mathrm{C}-\mathrm{V}_{\mathrm{o}}<\mathrm{C} \\
v_{1}=\mathrm{C}_{1} / \lambda_{1}=\left(\mathrm{C}-\mathrm{V}_{\mathrm{o}}\right) /((\mathrm{C}+1 / 2 \mathrm{a}) / \mathrm{f})<v
\end{gathered}
$$

When the light source (star) moves away from the observer at constant acceleration speed, the wavelength becomes bigger, both the frequency and light speed become smaller, and thus Redshift can be detected.

\section{Redshifts}

According to the Acceleration Doppler Effect, Redshift occurs whenever a light source moves away from the observer at an acceleration speed. However, there are another two Redshifts in the universe. Gravitational Redshift is caused by the massive gravitational field and Cosmological Redshift is induced by the shrinkage and acceleration of the Spacetime [4].

\section{Yangton and Yington Circulation}

Figure 3 is a schematic picture of Wu's Pair - a Yangton and Yington circulating pair [4]. The central acceleration $\left(a_{c}\right)$ can be derived as follows:

$$
\mathrm{a}_{\mathrm{c}}=\mathrm{dV} / \mathrm{dt}=(\mathrm{VdS} / \mathrm{r}) / \mathrm{dt}=\mathrm{V}(\mathrm{dS} / \mathrm{dt}) / \mathrm{r}=\mathrm{V}^{2} / \mathrm{r}
$$

Therefore,

$$
\mathrm{F}_{\mathrm{c}} \infty \mathrm{a}_{\mathrm{c}} \infty \mathrm{V}^{2} / \mathrm{r}
$$

Because,

$$
\begin{gathered}
\mathrm{F}_{\text {attraction }} \infty 1 /(2 \mathrm{r})^{2} \\
\mathrm{~F}_{\mathrm{c}}=\mathrm{F}_{\text {attraction }}
\end{gathered}
$$

Therefore,

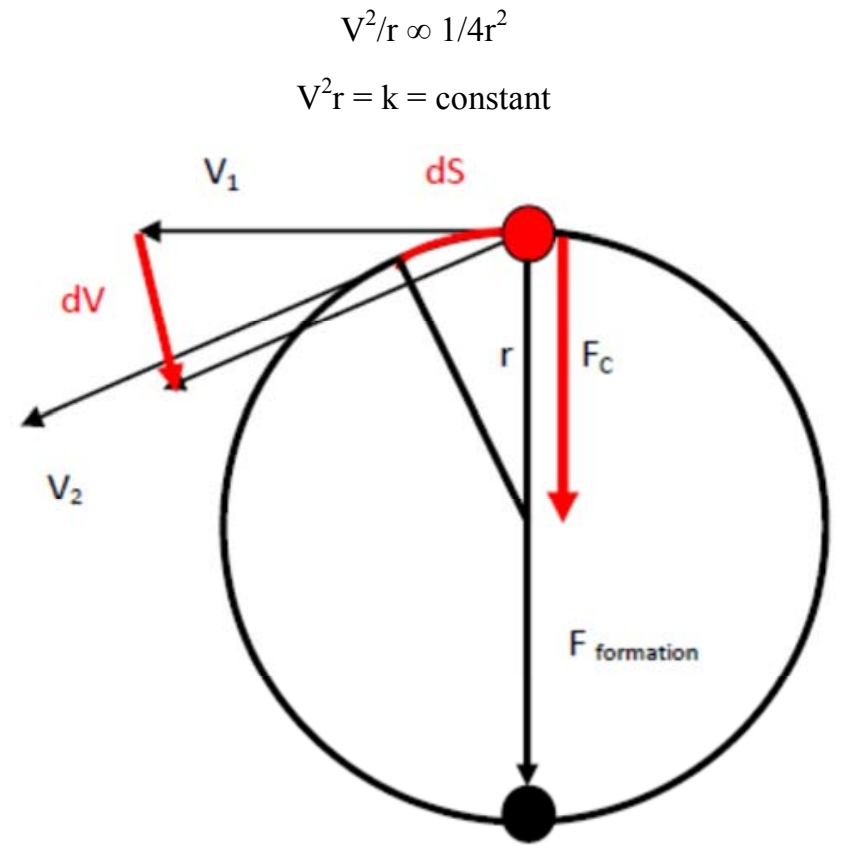

Figure 3. Schematic picture of a Wu's Pair. 


\section{Spacetime}

Spacetime $\left[\mathrm{t}_{\mathrm{yy}}, \mathrm{l}_{\mathrm{yy}}\right][9]$ is a four dimensional system $[\mathrm{x}, \mathrm{y}$, $z, t]$ based on the Wu's Unit Time $\left(t_{y y}\right)$, the period of Wu's Pair, and the Wu's Unit Length $\left(l_{\mathrm{yy}}\right)$, the size of Wu's Pair, at a reference point in the universe.

\subsection{Wu's Spacetime Theory}

The circulation period $\left(t_{y y}\right)$ and the size $\left(l_{y y}\right)$ of the circulation orbit of Wu's Pair are related to each other as follows:

Because,

$$
\mathrm{V}^{2} \mathrm{r}=\text { constant }
$$

And,

$$
\begin{gathered}
\mathrm{T}=2 \pi \mathrm{r} / \mathrm{V} \\
\mathrm{T}^{2}=4 \pi^{2} \mathrm{r}^{2} / \mathrm{V}^{2}=4 \pi^{2} \mathrm{r}^{3} / \mathrm{V}^{2} \mathrm{r}=4 \mathrm{k}_{1} \pi^{2} \mathrm{r}^{3} \\
\mathrm{~T}=\mathrm{k}_{2} \mathrm{r}^{3 / 2}
\end{gathered}
$$

Where $\mathrm{k}_{1}$ and $\mathrm{k}_{2}$ are constants.

Therefore, "Wu's Spacetime Theory" is represented as follows:

$$
\mathrm{t}_{\mathrm{yy}}=\mathrm{kl}_{\mathrm{yy}}^{3 / 2}
$$

Where $t_{y y}$ is the circulation period $(T)$ of Wu's Pair named as "Wu's Unit Time", $1_{\mathrm{yy}}$ is the size of the circulation orbit (2r) of Wu's Pair named as "Wu's Unit Length", and k is a constant.

\subsection{Velocity and Spacetime}

Because of "Wu's Spacetime Theory",

$$
\mathrm{t}_{\mathrm{yy}}=\mathrm{kl}_{\mathrm{yy}}^{3 / 2}
$$

Therefore,

$$
\mathrm{l}_{\mathrm{yy}} / \mathrm{t}_{\mathrm{yy}}=\mathrm{kl}_{\mathrm{yy}}{ }^{-1 / 2}
$$

Since velocity is proportional to $1_{\mathrm{yy}} / \mathrm{t}_{\mathrm{yy}}$ [4],

$$
\mathrm{V} \infty \mathrm{l}_{\mathrm{yy}} / \mathrm{t}_{\mathrm{yy}}
$$

Therefore,

$$
\mathrm{V} \infty 1_{\mathrm{yy}}^{-1 / 2}
$$

\subsection{Photon and Spacetime}

For a photon moving in vacuum,

$$
v=1 / t_{\mathrm{yy}}
$$

Also,

$$
\mathrm{t}_{\mathrm{yy}}=\mathrm{kl}_{\mathrm{yy}}^{3 / 2}
$$

Therefore,

$$
v \infty 1_{\mathrm{yy}}^{-3 / 2}
$$

Because,

$$
\mathrm{C} \infty 1_{\mathrm{yy}}{ }^{-1 / 2}
$$

And

$$
\lambda=\mathrm{C} / \mathrm{v}
$$

Therefore,

$$
\lambda \infty 1_{\mathrm{yy}}
$$

Where $v$ is frequency, $\mathrm{C}$ is light speed, $\lambda$ is wave length.

When universe grows older, the circulation speed $(\mathrm{V})$ of Wu's Pair becomes faster. Since $\mathrm{V}^{2} \mathrm{r}$ is always a constant $\left(\mathrm{V}^{2} \mathrm{r}\right.$ $=\mathrm{k}$ ) for an inter-attractive circulating pair such as Wu's Pair, the size of the circulation orbit (2r) of Wu's Pair becomes smaller. Also, the circulation period $(\mathrm{T}=2 \pi \mathrm{r} / \mathrm{V})$ of Wu's Pair is getting smaller. In another word, "Wu's Unit Time" $\left(\mathrm{t}_{\mathrm{yy}}=\right.$ $\mathrm{T})$ and "Wu's Unit Length $\left(1_{\mathrm{yy}}=2 \mathrm{r}\right)$ both become smaller. As a result, when universe grows older, the frequency $(v)$ of a photon becomes bigger, the light speed (C) becomes faster and the wave length $(\lambda)$ becomes smaller.

Also, for a high gravitational field, the circulation speed (V) of Wu's Pair becomes slower. Since $\mathrm{V}^{2} \mathrm{r}$ is always a constant $\left(\mathrm{V}^{2} \mathrm{r}=\mathrm{k}\right)$ for an inter-attractive circulating pair such as Wu's Pair, the size of the circulation orbit (2r) of Wu's Pair becomes bigger. Also, the circulation period $(\mathrm{T}=2 \pi \mathrm{r} / \mathrm{V})$ of Wu's Pair is getting bigger. In another word, "Wu's Unit Time" $\left(\mathrm{t}_{\mathrm{yy}}=\mathrm{T}\right)$ and "Wu's Unit Length $\left(\mathrm{l}_{\mathrm{yy}}=2 \mathrm{r}\right)$ both become bigger. As a result, for a high gravitational field, the frequency $(v)$ of a photon becomes smaller, the light speed (C) becomes slower and the wave length $(\lambda)$ becomes bigger.

Photon can be considered as a marker of the Spacetime of the light source. Photon's frequency ( $v$ ), light speed (C) and wave length $(\lambda)$ carry the information of $1_{y y}$ and $t_{y y}$ of the Spacetime of the light source deep into the universe. In other words, photon bears the DNA of the light source.

\subsection{Wu's Spacetime Shrinkage Theory}

Because of "Wu's Spacetime Theory",

$$
\mathrm{t}_{\mathrm{yy}}=\mathrm{kl}_{\mathrm{yy}}^{3 / 2}
$$

Therefore,

$$
\begin{gathered}
\mathrm{dt}_{\mathrm{yy}}=\mathrm{k}(3 / 2) \mathrm{l}_{\mathrm{yy}}{ }^{1 / 2} \mathrm{dl}_{\mathrm{yy}} \\
\mathrm{dl}_{\mathrm{yy}} / \mathrm{dt}_{\mathrm{yy}}=(\mathrm{k}(3 / 2))^{-1} \mathrm{l}_{\mathrm{yy}}{ }^{-1 / 2} \\
\mathrm{dl}_{\mathrm{yy}} / \mathrm{dt}_{\mathrm{yy}}=\mathrm{nl}_{\mathrm{yy}}{ }^{-1 / 2}
\end{gathered}
$$

And

$$
\mathrm{V}_{\mathrm{yy}}=\mathrm{nl}_{\mathrm{yy}}{ }^{-1 / 2}
$$

Where $\mathrm{V}_{\mathrm{yy}}$ is named as "Spacetime Shrinkage Rate" and $\mathrm{n}$ is a constant.

In comparison to those of the ancient universe, the size $\left(1_{\mathrm{yy}}\right)$ of Wu's Pair of the present Earth is getting smaller $\left(\mathrm{dl}_{\mathrm{yy}}\right.$ $<0$ ) and the period $\left(\mathrm{t}_{\mathrm{yy}}\right)$ of Wu's Pair is also getting shorter $\left(\mathrm{dt}_{\mathrm{yy}}<0\right)$. The Spacetime Shrinkage Rate $\left(\mathrm{V}_{\mathrm{yy}}\right)$ of Wu's Pair is inversely proportional to the square root of the size of the 
circulation orbit of Wu's Pair $\left(1_{\mathrm{yy}}{ }^{-1 / 2}\right)$. This is named as "Spacetime Shrinkage Theory".

\subsection{Wu's Spacetime Accelerating Shrinkage Theory}

Because of "Wu's Spacetime Theory",

$$
\mathrm{t}_{\mathrm{yy}}=\mathrm{kl}_{\mathrm{yy}}^{3 / 2}
$$

Therefore,

$$
\begin{gathered}
\mathrm{dt}_{\mathrm{yy}}=\mathrm{k}(3 / 2) \mathrm{l}_{\mathrm{yy}}{ }^{1 / 2} \mathrm{dl}_{\mathrm{yy}} \\
\mathrm{V}_{\mathrm{yy}}=\mathrm{dl}_{\mathrm{yy}} / \mathrm{dt}_{\mathrm{yy}}=(\mathrm{k}(3 / 2))^{-1} \mathrm{l}_{\mathrm{yy}}{ }^{-1 / 2} \\
\mathrm{dV}_{\mathrm{yy}}=(\mathrm{k}(3 / 2))^{-1}(-1 / 2) \mathrm{l}_{\mathrm{yy}}{ }^{-3 / 2} \mathrm{dl}_{\mathrm{yy}} \\
\mathrm{dV}_{\mathrm{yy}} / \mathrm{dt}_{\mathrm{yy}}=-\mathrm{ml}_{\mathrm{yy}}{ }^{-2}
\end{gathered}
$$

Therefore,

$$
\mathrm{a}_{\mathrm{yy}}=-\mathrm{ml}_{\mathrm{yy}}{ }^{-2}
$$

Where $a_{y y}$ is named as "Spacetime Shrinkage Acceleration Rate" and $\mathrm{m}$ is a constant.

In comparison to those of the ancient universe, the size $\left(1_{y y}\right)$ of Wu's Pair in the present Earth is getting smaller and the period $\left(t_{y y}\right)$ of Wu's Pair is getting shorter. Also the Spacetime Shrinkage Rate of Wu's Pair accelerates at a positive rate $\left(\mathrm{dV}_{\mathrm{yy}}>0\right)$ with respect to the shrinking $\mathrm{t}_{\mathrm{yy}}\left(\mathrm{dt}_{\mathrm{yy}}\right.$ $<0)$ that is inversely proportional to the square of the size of the circulation orbit of Wu's Pair $\left(\mathrm{l}_{\mathrm{yy}}{ }^{-2}\right)$. This is named as "Spacetime Accelerating Shrinkage Theory".

During Spacetime Shrinkage, although $\mathrm{t}_{\mathrm{yy}}$ and $\mathrm{l}_{\mathrm{yy}}$ become smaller, the relative amounts of $t_{w}$ and $l_{w}, t_{s}$ and $l_{s}$, also $t_{n}$ and $1_{n}$ remain unchanged, therefore for light generated on Earth, its speed, frequency and wavelength are always measured the same by the stationary observer on Earth. However, the universe becomes bigger measured by the shrinking $1_{\mathrm{s}}$ on Earth. In addition, because of the Spacetime Accelarating Shrinkage, the light from a star of ancient universe, a few million light years away has lower velocity and lower frequency but longer wavelength observed on Earth which is known as "Cosmological Redshift".

The theory of Accelerating Expansion of Universe requires a lot of external energy that is why scientists have imagined the existence of the mysterious Dark Energy [5] [10] in the universe. Since Dark Energy doesn't exist, also because that the potential energy can be converted to kinetic energy in the shrinking circulation process of Wu's Pair with no need of any external energy, Spacetime Accelerating Shrinkage Theory gives a better explanation to the phenomenon of the expansion and acceleration [10] of the universe.

\subsection{Wu's Laws of Spacetime}

\begin{tabular}{|c|c|c|c|c|c|}
\hline & & $\begin{array}{l}\text { Young } \\
\text { Universe }\end{array}$ & $\begin{array}{l}\text { Aged } \\
\text { Universe }\end{array}$ & $\begin{array}{l}\text { High } \\
\text { Gravity }\end{array}$ & $\begin{array}{l}\text { Low } \\
\text { Gravity }\end{array}$ \\
\hline $\begin{array}{l}\text { Wu's Pair } \\
1_{\mathrm{yy}}(=2 \mathrm{r})\end{array}$ & $1_{\mathrm{yy}}=2 \mathrm{r}$ & Large & Small & Large & Small \\
\hline $\mathrm{t}_{\mathrm{yy}}(=\mathrm{T})$ & $\mathrm{t}_{\mathrm{yy}} \infty \mathrm{l}_{\mathrm{yy}}^{3 / 2}$ & Large & Small & Large & Small \\
\hline V & $\mathrm{V} \infty 1_{\mathrm{yy}}^{-1 / 2}$ & Small & Large & Small & Large \\
\hline$V_{\text {yy }}$ & $\mathrm{V}_{\mathrm{yy}} \infty \mathrm{l}_{\mathrm{yy}}{ }^{-1 / 2}$ & Small & Large & Small & Large \\
\hline $\begin{array}{l}a_{y y} \\
\text { Photon }\end{array}$ & $\mathrm{a}_{\mathrm{yy}} \infty-\mathrm{l}_{\mathrm{yy}}{ }^{-2}$ & Small & Large & Small & Large \\
\hline$v$ & $\begin{array}{l}v=1 / t_{y y} \infty \\
1_{y y}^{-3 / 2}\end{array}$ & Small & Large & Small & Large \\
\hline $\mathrm{C}$ & $\mathrm{C} \infty 1_{\mathrm{yy}}{ }^{-1 / 2}$ & Small & Large & Small & Large \\
\hline$\lambda$ & $\begin{array}{l}\lambda=\mathrm{C} / \nu \infty \\
1_{\mathrm{yy}}\end{array}$ & Large & Small & Large & Small \\
\hline
\end{tabular}

Table 1 summarizes "Wu's Laws of Spacetime" of Wu's Pair with respect to $\mathrm{l}_{\mathrm{yy}}, \mathrm{t}_{\mathrm{yy}}, \mathrm{V}_{\mathrm{yy}}$ and $\mathrm{a}_{\mathrm{yy}}$; and also those of photon with respect to $v, \mathrm{C}$ and $\lambda$, in both gravitational field and age of the universe.
Table 1. Wu's Laws of Spacetime.

\section{Hubble's Law Based on Wu's Spacetime Accelerating Shrinkage Theory}

The discovery of the linear relationship between Redshift and distance, coupled with a supposed linear relation between recessional velocity and Redshift, yields a straight forward mathematical expression for "Hubble's Law" (Figure 4) [6] as follows:

$$
\mathrm{V}=\mathrm{H}_{0} \mathrm{D}
$$

Where

- $\mathrm{V}$ is the recessional velocity, expressed in $\mathrm{km} / \mathrm{s}$.

- $\mathrm{H}_{0}$ is Hubble's constant and corresponds to the value of $\mathrm{H}$ (often termed the Hubble parameter which is a value that is time dependent and which can be expressed in terms of the scale factor) in the Friedmann equations taken at the time of observation denoted by the subscript " 0 ". This value is the same throughout the universe for a given comoving time.

- $\mathrm{D}$ is the proper distance (which can change over time, unlike the comoving distance, which is constant) from the galaxy to the observer, measured in mega parsecs (Mpc), in the 3-space defined by given cosmological time. (Recession velocity is just $\mathrm{V}=\mathrm{dD} / \mathrm{dt}$ ).

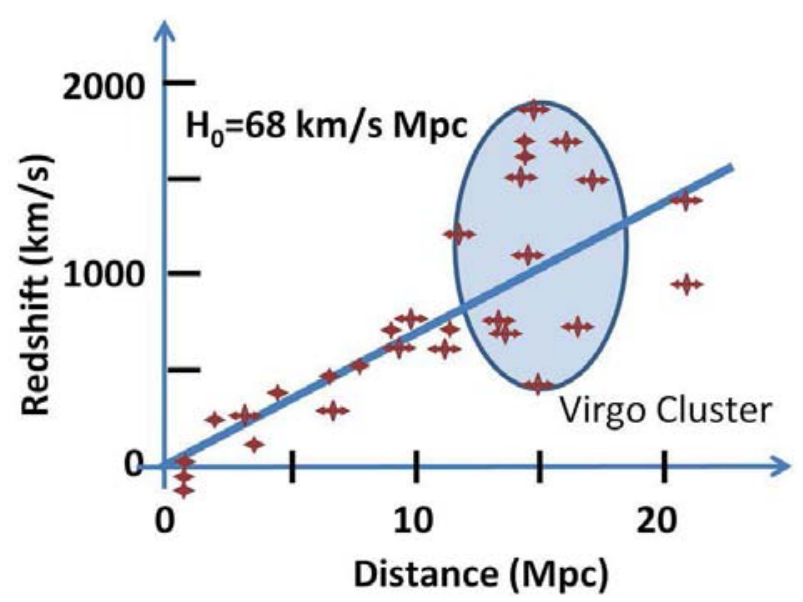

Figure 4. Hubble's Law - the linear relationship between Redshift and Proper Distance. 
According to Hubble's Law, there is a linear relation between recessional velocity $(\mathrm{V})$ and $\operatorname{Redshift}\left(\lambda-\lambda_{0}\right) / \lambda_{0}$,

$$
\mathrm{V} \infty\left(\lambda-\lambda_{0}\right) / \lambda_{0}
$$

Where $\lambda_{0}$ is the present wave length on Earth.

And,

$$
\lambda \infty 1_{\mathrm{yy}}
$$

Therefore,

$$
\mathrm{V} \infty\left(1_{\mathrm{yy}}-1_{\mathrm{yy} 0}\right) / 1_{\mathrm{yy} 0}
$$

Where $1_{\mathrm{yy} 0}$ is the present Wu's Unit Length on Earth. Also, D is found to be proportional to the Redshift,

$$
\mathrm{D} \infty\left(\lambda-\lambda_{0}\right) / \lambda_{0}
$$

Therefore,

$$
\mathrm{D} \infty\left(1_{\mathrm{yy}}-1_{\mathrm{yy} 0}\right) / 1_{\mathrm{yy} 0}
$$

Because both $\mathrm{V}$ and $\mathrm{D}$ are proportional to $\left(1_{\mathrm{yy}}-1_{\mathrm{yy} 0}\right) / 1_{\mathrm{yy} 0}$ (named as Spacetime Shrinkage Factor), Hubble's Law goes very well with Wu's Spacetime Accelerating Shrinkage Theory. Therefore, instead of that the universe is expanding and accelerating, Wu's Unit Length $\left(1_{\mathrm{yy}}\right)$, or in other words, Wu's Spacetime is shrinking and accelerating.

\section{Conclusion}

Instead of Doppler Effect for Non-Inertia Transformation, Acceleration Doppler Effect is introduced and derived successfully to explain the Redshift phenomenon in Inertia Transformation process. Specitime Shrinkage factor is defined and Hubble's Law and Cosmological Redshift can be interpreted by Wu's Spacetime Accelerating Shrinkage Theory. In addition, Wu's Laws of Spacetime of Wu's Pair with respect to $1_{y y}, t_{y y}, V_{y y}$ and $a_{y y}$, as well as Wu's Laws of Spacetime of photon with respect to $v, C$ and $\lambda$, in both gravitational field and age of universe are derived and summarized.

\section{References}

[1] https://en.wikipedia.org/wiki/Redshift.

[2] Alec Eden The search for Christian Doppler, Springer-Verlag, Wien 1992. Contains a facsimile edition with an English translation.

[3] Edward T. H. Wu. "Light Speed in Vacuum is not a Constant and Time Doesn't Change with Velocity-Discrepancies Between Relativities and Yangton \& Yington Theory". American Journal of Modern Physics. Vol. 4, No. 6, 2015, pp. 367-373. doi: 10.11648/j.ajmp.20150406.12.

[4] Edward T. H. Wu. "Time, Space, Gravity and Spacetime Based on Yangton \& Yington Theory, and Spacetime Shrinkage Versus Universe Expansion". American Journal of Modern Physics. Vol. 5, No. 4, 2016, pp. 58-64. doi: 10.11648/j.ajmp.20160504.13

[5] Peebles, P. J. E. and Ratra, Bharat (2003). "The cosmological constant and dark energy". Reviews of Modern Physics 75 (2): 559-606. arXiv: astro-ph/0207347. Bibcode: 2003 RvMP.75.559 P. doi: 10.1103/RevModPhys.75.559.

[6] Hubble, E. (1929). "A relation between distance and radial velocity among extra-galactic nebulae". Proceedings of the National Academy of Sciences.15 (3): 168-73. Bibcode: 1929PNAS...15..168H. doi: 10.1073/pnas.15.3.168.

[7] Edward T. H. Wu, "Yangton and Yington - A Hypothetical Theory of Everything", Science Journal of Physics, Volume 2015, Article ID sjp-242, 6 Pages, 2015, doi: $10.7237 / \mathrm{sjp} / 242$.

[8] Edward T. H. Wu. "Mass, Momentum, Force and Energy of Photon and Subatomic Particles, and Mechanism of Constant Light Speed Based on Yangton \& Yington Theory". American Journal of Modern Physics. Vol. 5, No. 4, 2016, pp. 45-50. doi: 10.11648/j.ajmp.20160504.11.

[9] Catoni, F.; et al. (2008). Mathematics of Minkowski Space. Frontiers in Mathematics. Basel: Birkhauser Verlag. doi: 10.1007/978-3-7643-8614-6. ISBN 978-3-7643-8613-9. ISSN1660-8046.

[10] Frieman, Joshau A.; Turner, Michael S.; Huterer, Dragan. "Dark Energy and the Accelerating Universe" (PDF). Annu. Rev. Astron. Astrophys. arXiv: 0803.0982 v 1. Retrieved April 1, 2016. 